\title{
ANALISIS PENGARUH PELATIHAN RESUSITASI JANTUNG PARU (RJP) DEWASA TERHADAP RETENSI PENGETAHUAN DAN KETRAMPILAN RJP PADA MAHASISWA KEPERAWATAN DI YOGYAKARTA
}

\author{
Linda Widyarani ${ }^{1}$ \\ 1Dosen Departement Keperawatan Gawat Darurat dan Manajemen Bencana \\ Akademi Keperawatan Notokusumo Yogyakarta \\ email: lindawidyarani@gmail.com
}

\begin{abstract}
Cardiac arrest is a major public health problem affecting thousands of individuals each year in both out-of-hospital and in-hospital setting. High quality of cardiopulmonary resuscitation (CPR) provide return of spontaneous after cardiac arrest, but majority of nursing students feel unconfident to practice CPR. The aim of the study was to assess the effect of CPR training program on knowledge and practices of nursing students in Yogyakarta. The study design was quasi-experimental and one group pretest - posttest design. A questionnaire was applied to the students before CPR training, then the student were informed about adult CPR by the researchers and all of the students practice CPR on a Resusci-Anne manikin. One-months after this training the same questionnaire and skills checklist of CPR were applied. Sixty five students of nursing participated in this study. This research shows CPR training significantly positive impact cognitive and skills performance in nursing students. While the average CPR knowledge score of these students was $\pm 44,43$, before CPR training, this average increased to $\pm 89,64$ after CPR training and decreased to $\pm 77,54$ after one month CPR training. Skill score of the students one month after the CPR skill training was $\pm 70,61$. Nursing students tend to forget theoretical and applied CPR training after one month. Hence there is a need for continuous CPR training and education and repeating the skills at regular intervals ever after they have graduated to ensure sustainability in the CPR skills.
\end{abstract}

Keywords: cardiopulmonary resuscitation, bystander CPR, training

\begin{abstract}
Henti jantung merupakan penyebab kematian utama pada kasus kegawatdaruratan kardiovaskuler, baik pada setting prehospital (OHCA) maupun intrahospital. Resusitasi Jantung Paru (RJP) yang berkualitas dapat mengoptimalkan return of spontaneous circulation pada OHCA, tetapi banyak mahasiswa keperawatan tidak percaya diri dalam melakukan prosedur ini sehingga mereka membutuhkan pelatihan RJP, agar dapat berespon cepat, tanggap dan akurat dalam memberikan pertolongan pada korban OHCA. Penelitian ini menguji pengaruh pelatihan RJP dewasa terhadap retensi pengetahuan dan ketrampilan RJP pada mahasiswa keperawatan di Yogyakarta. Jenis penelitian quasi experimental dengan design one group pretest - posttest. Posttest diberikan dua kali, yaitu sesaat sesudah pelatihan dan sebulan sesudah pelatihan. Jumlah sampel yaitu 65 orang. Analisa data menggunakan pair t-test. Hasilnya, pelatihan RJP berpengaruh positif terhadap pengetahuan dan ketrampilan bystander RJP dengan $p$-value $0,000(<0,001)$. Rerata skor awal pengetahuan $\pm 44,43$, rerata skor sesaat sesudah pelatihan $\pm 89,64$ dan rerata skor sebulan sesudah pelatihan adalah $\pm 77,54$. Rata-rata skor ketrampilan sebelum
\end{abstract}


pelatihan adalah $\pm 35,55$, rerata skor sesaat setelah pelatihan $\pm 91,80$ dan rerata skor sebulan setelah pelatihan $\pm 70,61$. Berdasarkan hasil wawancara dengan responden, penurunan retensi pengetahuan dan ketrampilan mahasiswa sebulan sesudah pelatihan RJP disebabkan karena mahasiswa kurang terpapar kasus pasien dengan henti jantung yang membutuhkan tindakan RJP.

Kata Kunci: resusitasi jantung paru, pelatihan, bystander RJP

\section{PENDAHULUAN}

Henti jantung yang terjadi di luar rumah sakit, atau dikenal dengan istilah Out of Hospital Cardiac Arrest (OHCA) merupakan salah satu kasus kegawatdaruratan yang menjadi penyebab kematian utama di Amerika dan Eropa. Secara global, angka kejadian OHCA cenderung meningkat dari tahun ke tahun. Di Unites State, angka kejadian OHCA sudah mencapai 180.000 - 450.000 kasus per tahun sedangkan di Netherlands, Ireland dan Cina, insidensi OHCA juga sudah mencapai 50 - 100 orang per 100.000 penduduk per tahun (Fishman et al., 2010; Deo et al., 2012).

Di Asia Tenggara, yaitu Singapura, insidensi OHCA dalam kurun waktu tiga bulan sejak November 2001 Januari 2002 mencapai 93 pasien (Lim et al., 2002). Di Malaysia, yaitu di Hospital Universiti Sains Malaysia (HUSM), angka kejadian OHCA dalam kurun waktu satu tahun sejak Maret 2005 sampai Maret 2006 mencapai 63 pasien, dan hanya 19 pasien diantaranya berhasil kembali ke kondisi Return of Spontaneous Circulation (ROSC) setelah pemberian tindakan RJP di IGD (Chew et al., 2008). Insidensi OHCA juga meningkat seiring dengan peningkatan usia, pada laki-laki usia 50 tahun insidensi OHCA mencapai 100 per 100.000 penduduk per tahun dan meningkat pada laki-laki usia 80 tahun mencapai 800 per 100.000 penduduk per tahun (Liong., et al., 2010). Chung \&
Wong., (2005) mengemukanan bahwa OHCA paling sering terjadi di rumah, yaitu mencapai $80 \%$ dan $20 \%$ terjadi di luar rumah.

Di Indonesia, belum ada data statistik tentang angka kejadian OHCA, akan tetapi beberapa kejadian sudah menyerang masyarakat di Indonesia, antara lain Adjie Massaid, seorang artis sekaligus politikus mengalami kematian akibat OHCA dan Ida Kusumah, seorang artis perempuan juga mengalami kematian akibat OHCA. Selain itu, Ricky Joe, seorang presenter sepak bola, Benyamin S, seorang aktor senior dan juga Jojon, seorang komedian terkenal di Indonesia juga mengalami kematian akibat OHCA (Harian Kompas, 2011). Fenomena di Indonesia adalahperan bystander belum terimplementasi secara baik sehingga pasien dengan $\mathrm{OHCA}$ seringkali tidak mendapatkan early RJP, RJP diberikan jika pasien sudah berada di rumah sakit.

OHCA didefinisikan sebagai kondisi berhentinya aktivitas mekanik jantung yang ditandai dengan tidak adanya tanda sirkulasi jantung dan kejadiannya terjadi di luar rumah sakit (Berg., et al., 2010). Pasien dengan OHCA umumnya mempunyai gambaran EKG lethal dengan kriteria ventrikuler takikardia (VT), ventrikuler fibrilasi (VF), pulseless electrical activity (PEA) dan asystole. Semakin meningkatnya angka kejadian OHCA dan juga untuk meningkatkan angka kelangsungan hidup pasien post-OHCA maka 
dibutuhkan suatu strategi implementasi penanganan OHCA. Early-RJP merupakan strategi implementasi yang direkomendasikan oleh American Heart Association (AHA) (Berg et al., 2010). Cappuci et al., (2002) mengemukakan bahwa early-RJP terbukti mampu meningkatkan angka kelangsungan hidup sampai tiga kali lipat pada pasien post $\mathrm{OHCA}$, dibandingkan pasien yang tidak mendapatkan early-RJP.

Early-RJP dapat diinisiasi oleh bystander. Early-RJP oleh bystander, sementara waktu mampu mempertahankan perfusi jantung dan otak akan kebutuhan oksigen sebelum anggota tim Emergency Medical Services(EMS) dan ambulans datang di lokasi. Pasien yang mengalami OHCA, angka kelangsungan hidup menurun 7 $9 \%$ per menit apabila tidak diberikan early-RJP (Chewet al., 2008). Berg et al., (2010) menyatakan bahwa pemberian early-RJP oleh bystander terbukti meningkatkan angka kelangsungan hidup pasien post OHCA. Definisi bystanderadalah upaya pemberian earlyRJP yang dilakukan oleh seseorang yang sudah pernah mengikuti pelatihan pemberian RJP, selain dari anggota tim EMS (Sasson et al., 2010).

Mahasiswa merupakan bagian dari masyarakat dimana turut bertanggung jawab terhadap permasalahan ini, sehingga RJP merupakan keterampilan yang harus dikuasai oleh mahasiswa. RJP yang berkualitas dapat mengoptimalkan return of spontaneus circulation, tetapi banyak mahasiswa kedokteran tidak percaya diri dalam melakukan prosedur ini (Behrend, 2011). Mahasiswa keperawatan merupakan salah satu bystander RJP yang membutuhkan pengetahuan dan juga ketrampilan dalam melakukan early-RJP, sehingga mereka membutuhkan pelatihan RJP, agar setelah lulus, mereka yang nantinya bekerja sebagai perawat dapat berespon cepat, tanggap dan efektif dalam memberikan pertolongan pada korban dengan OHCA. Kemampuan tersebut harus selalu disiapsiagakan dan diperbaharui sesuai dengan perkembangan ilmu yang ada (Nori et al., 2012). McNallyet al., (2011) menyebutkan bahwa pelatihan RJP mampu meningkatkan pengetahuan dan juga ketrampilanbystanderRJP, kemampuan kompresi dada bystandersebelum mendapat pelatihan hanya $29,5 \%$ sedangkan sesudah pelatihan RJP, kemampuan bystander mencapai $99,2 \%$. Selain itu, tingkat percaya diri bystander juga meningkat, yaitu mencapai 99,2\% sesudah pelatihan RJP, sedangkan sebelum pelatihan RJP hanya $26,9 \%$. Berdasarkan latar belakang diatas, perlu dikaji tentang pengetahuan dan ketrampilan mahasiswa keperawatan sebagai bystander sebelum dan sesudah pelatihan RJP. Oleh karena itu, peneliti tertarik melakukan penelitian dengan judul "Analisis Pengaruh Pelatihan Resusitasi Jantung Paru (RJP) Dewasa terhadap Retensi Pengetahuan dan Ketrampilan RJP pada Mahasiswa Keperawatan di Yogyakarta."

\section{METODE PENELITIAN}

Penelitian ini merupakan penelitian kuantitatif dengan jenis quasi experimental dengan design one group pretest - posttest. Design one group pretest - posttest adalah design penelitian dimana suatu kelompok diberikan perlakuan, namun sebelumnya diberikan pretest dan selanjutnya dilakukan posttest (Wasis, 2006).

Penelitian ini dilakukan pada bulan Maret sampai Mei 2017. Populasi pada penelitian ini adalah seluruh mahasiswa semester V DIII Keperawatan, setelah dipilih sesuai dengan kriteria inklusi didapatkan jumlah sampel yaitu 65 orang. Adapun kriteria inklusi pada penelitian ini adaah mahasiswa semester $V$ program studi DIII Keperawatan AKPER Notokusumo, bersedia menjadi responden penelitian 
dengan mengisi informed consent, dan tidak sedang sakit selama proses pengambilan data.

Dalam penelitian ini, subjek penelitian, yang dalam penelitian ini disebut sebagai bystander terlebih dahulu diberikan tes awal (pretest) untuk mengetahui sejauh mana pengetahuan dan ketrampilannya. Selanjutnya, subjek penelitian diberikan pelatihan RJP dan pada tahap akhir, subjek penelitian diberikan posttest untuk mengetahui sejauh mana pengaruh pelatihan RJP terhadap pengetahuan dan ketrampilan bystander. Posttest diberikan dua kali, yaitu sesaat sesudah pelatihan dan sebulan sesudah pelatihan.

Instrumen penelitian dalam penelitian ini mengacu pada Written Exam: Version A 2011 American Heart Association (AHA). Written Exam: Version A 2011 American Heart Association (AHA) terdiri dari 20 pertanyaan multiple choice. Pengambilan sampel dengan teknik probability sampling yaitu dengan simple random sampling. Analisa data menggunakan pair t-test.

\section{HASIL DAN PEMBAHASAN}

Pada penelitian ini, karakteristik responden berdasarkan usia menunjukkan usia minimal adalah 20 tahun dan usia maksimal adalah 26 tahun, dengan mean 22,78 . Berdasarkan jenis kelamin, sebagian besar responden berjenis kelamin perempuan $(76,92 \%)$.

\section{Tabel 1. Data Karakteristik Responden berdasarkan usia dalam tahun ( $n=65$ orang)}

\begin{tabular}{ccccc}
\hline Usia & Mean & Median & Modus & SD \\
\hline $20-26$ & 22,78 & 23 & 23 & 1,16 \\
\hline \multicolumn{5}{l}{ Sumber Data : Data Primer (2017) }
\end{tabular}

Tabel 2. Data Karakteristik Responden berdasarkan jenis kelamin ( $n=65$ orang)

\begin{tabular}{llc}
\hline \multicolumn{1}{c}{ Jenis Kelamin } & $\mathbf{n}$ & $\mathbf{\%}$ \\
\hline Laki-laki & 15 & 23,08 \\
\hline Perempuan & 50 & 76,92 \\
\hline Total & 65 & $100 \%$ \\
\hline
\end{tabular}

Sumber Data: Data Primer (2017)

Pada penelitian ini, kemampuan kognitif bystander RJP diartikan sebagai kemampuan kognitif bystander dalam menginterpretasikan informasi tentang tindakan early RJP pada pasien OHCA, sebelum, sesaat sesudah, dan satu bulan sesudah pelatihan RJP. Berdasarkan tabel berikut tertuang rata-rata skor kemampuan kognitif saat pretest, posttest dan sebulan sesudah pelatihan RJP.

Tabel 3. Data Kemampuan Kognitif dan

Skill Responden Sebelum, Sesaat dan Sebulan Sesudah Pelatihan RJP

\begin{tabular}{llll}
\hline $\begin{array}{l}\text { Variabel } \\
\text { yang } \\
\text { dinilai }\end{array}$ & $\begin{array}{l}\text { Sebelum } \\
\text { pelatihan }\end{array}$ & $\begin{array}{l}\text { Sesaat } \\
\text { sesudah } \\
\text { pelatihan }\end{array}$ & $\begin{array}{l}\text { Sebulan } \\
\text { sesudah } \\
\text { pelatihan }\end{array}$ \\
\hline $\begin{array}{l}\text { Kemampu } \\
\text { an kognitif }\end{array}$ & $44,43 \pm 5,44$ & $89,64 \pm 5,56$ & $77,54 \pm 6,86$ \\
\hline $\begin{array}{l}\text { Kemampu } \\
\text { an skill }\end{array}$ & $33,55 \pm 6,51$ & $91,80 \pm 6,25$ & $70,61 \pm 6,14$ \\
\hline
\end{tabular}

Sumber Data: Data Primer (2017)

Pada penelitian ini, rata-rata skor pretest kemampuan kognitif bystander RJP adalah $\pm 44,43$, sedangkan rata-rata skor sesaat sesudah pelatihan RJP adalah $\pm 89,64$ dan sebulan sesudah pelatihan RJP adalah $\pm 77,54$. Hasil penelitian ini didukung oleh penelitian Bobrow et al (2012) bahwa rata-rata skor kemampuan kognitif bystander RJP sebelum pelatihan yaitu $\pm 52,04$ dan skor kemampuan kognitif segera setelah pelatihan meningkat menjadi $\pm 84,34$ dan sebulan setelah pelatihan menunjukkan adanya penurunan yaitu menjadi $\pm 78,59$. 
Pada penelitian ini, rata-rata skor kemampuan skill bystander RJP sebelum pelatihan yaitu $\pm 35,55$ sedangkan segera setelah pelatihan meningkat menjadi $\pm 91,80$ dan sebulan setelah pelatihan, mengalami penurunan menjadi $\pm 70,61$. McNallyet al.,(2011) mendukung hasil penelitian ini bahwa kemampuan skill RJP sebelum diberikan pelatihan hanya \pm 29 , sedangkan setelah diberikan pelatihan, kemampuan skill RJP mencapai $\pm 80,2$ dan sebulan sesudah pelatihan RJP menurun menjadi $\pm 68,4$. Hasil penelitian ini menunjukkan adanya penurunan retensi pengetahuan dan ketrampilan mahasiswa sebulan sesudah pelatihan RJP.

Berdasarkan hasil wawancara
dengan responden ditemukan data bahwa responden kurang terpapar dengan kasus henti jantung sehingga lupa dengan prosedur tindakan RJP. Hasil penelitian ini senada dengan Puspita (2015) yang menjelaskan bahwa seseorang cenderung lupa karena tergantung pada sesuatu yang diamati, situasi, proses pengamatan yang berlangsung dan waktu. Pengetahuan sebagai hasil dari proses belajar sangat dipengaruhi oleh waktu sejak memperoleh pemaparan, dan akan cenderung menurun secara logaritmik dari waktu ke waktu. Penelitian ini menunjukkan pelatihan RJP berpengaruh positif terhadap kemampuan kognitif dan skill bystander RJP dengan p-value 0,000 $(<0,001)$ yang tertuang pada tabel berikut.

\section{Tabel 4. Hasil Analisa Data Pair t-test Pengaruh Pelatihan RJP terhadap Kemampuan Kognitif dan Skill bystander RJP}

\begin{tabular}{cc}
\hline Variabel & $\begin{array}{c}\text { Pelatihan RJP } \\
(p \text {-value })\end{array}$ \\
\hline Kemampuan Kognitif RJP & 0,000 \\
\hline Kemampuan Skill RJP & 0,000 \\
\hline Sumber Data: Data Primer (2017)
\end{tabular}

Hasil penelitian ini didukung oleh McNallyet al (2011) bahwa pelatihan RJP berpengaruh secara signifikan terhadap kemampuan kognitif dan skill bystander RJP ( $p$ - value $<0,001)$. Pada penelitian ini, keterampilan responden dalam melakukan Resusitasi Jantung Paru dinilai dari indikator sebagai berikut: 1) tahapan respon kegawatdaruratan, yaitu pastikan keamanan, cek respon korban, panggilan telepon bantuan; 2) posisi tangan, yaitu jumlah wrong hand position (kali); 3) RJP berkualitas, yaitu rata-rata kedalaman kompresi $(\mathrm{mm})$, rata-rata kecepatan kompresi (kali/menit), jumlah incomplete release (kali) serta jumlah ventilasi efektif (kali); dan 4) durasi kompresi=ventilasi (detik).

Responden menunjukkan ketidakmampuan untuk memberikan tiupan yang benar dan tepat sehingga tiupan yang diberikan menjadi kurang bahkan tidak efektif. Selain itu ketidakpercayaan diri responden untuk memberikan tiupan pada mulut manikin yang telah disediakan juga turut berkontribusi terhadap kemampuan memberikan ventilasi yang efektif. Pencapaian ketrampilan tindakan RJP agar menghasilkan kualitas yang baik harus dilakukan dengan teknik yang benar mulai dari penempatan posisi tangan yang tepat, tekanan yang dibutuhkan untuk menghasilkan kedalaman yang maksimal, kecepatan yang dihasilkan adekuat serta pemberian bantuan nafas yang efektif, tentunya pencapaian ketrampilan tersebut tidak dapat diperoleh hanya dengan pelatihan yang sifatnya singkat, harus dilakukan pengulangan dan latihan dengan interval waktu tertentu untuk menjaga ketrampilan RJP yang dimiliki tetap baik.

\section{SIMPULAN DAN SARAN}

Pelatihan RJP berpengaruh positif terhadap pengetahuan dan ketrampilan bystander RJP dengan pvalue $0,000 \quad(<0,001)$. Rata-rata skor awal pengetahuan bystander RJP pada penelitian ini adalah $\pm 44,43$, sedangkan rata-rata skor sesaat sesudah pelatihan 
RJP adalah $\pm 89,64$ dan sebulan sesudah pelatihan RJP adalah $\pm 77,54$. Rata-rata skor ketrampilan bystander RJP sebelum pelatihan adalah $\pm 35,55$ sedangkan sesaat setelah pelatihan RJP adalah $\pm 91,80$ dan pada sebulan setelah pelatihan RJP adalah $\pm 70,61$. Penelitian ini menunjukkan pelatihan RJP berpengaruh positif terhadap pengetahuan dan ketrampilan bystander RJP dengan $p$-value $<0,000$.

Penurunan retensi pengetahuan dan ketrampilan mahasiswa sebulan sesudah pelatihan RJP disebabkan karena mahasiswa kurang terpapar kasus pasien dengan henti jantung yang membutuhkan tindakan RJP. Pencapaian kemampuan kognitif dan ketrampilan RJP yang efektif tentunya tidak dapat diperoleh hanya dengan pelatihan yang sifatnya singkat, harus dilakukan pengulangan dan latihan dengan interval waktu tertentu untuk menjaga ketrampilan RJP yang dimiliki tetap baik

\section{DAFTAR PUSTAKA}

Berg, R.A., Hemphill, R., Abella, B.S., Aufderheide, DM., Cave, D.M., Hazinski, M.F., Lerner, B., Rea, T.D., Sayre, M.R., Swor, R.A. (2010). Adult Basic Life Support: 2010 American Heart Association Guidelines for Cardiopulmonary Resuscitation and Emergency Cardiovascular Care. 122. p: $685-705$

Bobrow, B.J., Spaite, D.W., Berg, R.A., Stolz, U., Sanders, A.B., Kern, K.B. (2012). Chest Compression-Only CPR by Lay Rescuers and Survival From Out-of-Hospital Cardiac Arrest. The Journal of the American Medical Association. 304 (13). p: 1447 - 1454
Behrend T, Heineman J, Wu L, Burk C, Duong N, Munoz M, Pruett $M$, Seropian M, Dillman D. (2011) Retention of Cardiopulmonary Resuscitation Skills in Medical Students Utilizing a High-Fidelity Patient Simulator. Medical Student Research Journal;1(Winter):1-4

Capucci, A., Aschieri, D., Piepoli, M.F., Bardy G.H., Iconomu, E., Arvedi, M. (2002). Tripling Survival from Sudden Cardiac Arrest via Early Defibrillation without Traditional Education in Cardiopulmonary Resuscitation. Circulation. 106. p: 1065 - 1070

Chew, KS., Idzwan, ZM., Hisamuddin, NAR., Aasim, WAW. (2008). Outcomes of Cardiopulmonary Resuscitation Performed in Emergency Department, Hospital Universiti Sains Malaysia. Medical Journal Malaysia. 63(1): 4 - 8

Chew, KS., Idzwan, M., Hishamuddin, NAR., Wan, WA., Kamaruddin, J. (2008). How frequent is bystander cardiopulmonary resuscitation performed in the community of Kota Bharu, Malaysia. Singapore Medical Journal. 49(8):636 - 646

Chung, CH., Wong, PCY. (2005). A six year prospective study of out of - hospital cardiac arrest managed by a voluntary ambulance organization. Hongkong Journal of Emergency Medicine. 12(3):140 - 147

Deo, R., Albert, C.M. (2012). Epidemiology and Genetics of Sudden Cardiac Death. Circulation. 125. p: 620-637 
Fishman, G.I., Chugh, S.S., DiMarco, J.P., Albert, C.M., Anderson, M.E. (2010). Sudden Cardiac Death Prediction and Prevention. Report from a National Heart, Lung, and Blood Institute and heart Rhythm Society Workshop. Circulation. 122. p: $2335-2348$

Harian Kompas. 5 Februari (2011). Adjie Massaid dan Kematian Mendadak. Harian Kompas [Online]. Dikutip dari: http://health.kompas.com/index. php/read/2011/02/05/10302115/ Adjie.Massaid.dan.Kematian.Me ndadak

Harian Kompas. 23 Maret (2013). Hikmah di Balik Kepergian Ricky Jo. Harian Kompas [Online]. Dikutip dari: http://health.kompas.com/read/2 013/03/23/09542054/hikmah.di.b alik.kepergian.ricky.jo

Lim, GH., Seow, E. (2002). Resuscitation for Patients with out - of hospital cardiac arrest: Singapore. Prehospital Disaster Medical. 17(2):96 - 101

Leong, BSH. (2011). Bystander CPR and Survival. Singapore Medical Journal. 52(8). p: 573575

McNally, B., Robb, R., Mehta, M., Vellano, K., Valderrama, A.L., Yoon, P.W., Sasson, C. (2011). Out-of-Hospital Cardiac Arrest Surveillance - Cardiac Arrest Registry to Enhance Survival (CARES), United States,
October 1, 2005 - December 31, 2010. Centers for Disease Control and Prevention. Morbidity and Mortality Weekly Report. 60 (8). 1 - 6

Nori, JM., Saghafinia, M., Motamedi, MH., Hosseini, MK. (2012). CPR training for Nurses: How often is it necessary? Iran Red Crescent Medical Journal. 14(2): 104 107

Puspita, I., D. (2015). Retensi Pengetahuam, Sikap, dan Perilaku Pasca Pelatihan Gizi Seimbang pada Siswa Kelas 5 dan 6 di 10 Sekolah Dasar Terpilih Kota Depok Tahun 2012. Bina Widya. Vol. 26 Nomor 1. p: 18-27

Sasson, C., Meischke, H., Abella, B.S., Berg, R.A., Bobrow, B.J., Chan, P.S., Root, E.D., Heisler, M., Levy, J.H., Link, M., Masoudi, F., Ong, M., Sayre, M.R. (2013). Increasing Cardiopulmonary Resuscitation Provision in Communities With Low Bystander Cardiopulmonary Resuscitation Rates A Science Advisory From the American Heart Association for Healthcare Providers, Policymakers, Public Health Departments, and Community Leaders. Circulation. 127. p: $1-9$

Wasis. (2006). Pedoman Riset Praktis untuk Profesi Perawat. Jakarta: EGC. 